\title{
Reply to "Takotsubo Syndrome in Patients with COVID-19: a Systematic Review of Published Cases"
}

\author{
Andrea Falcetta ${ }^{1}$ (D) - Eleonora Bonfanti ${ }^{2} \cdot$ Giuseppe Lauria $^{1}$ \\ Accepted: 16 December 2020 / Published online: 3 January 2021 \\ (C) The Author(s), under exclusive licence to Springer Nature Switzerland AG part of Springer Nature 2021
}

Dear authors, we greatly appreciated the systematic review and analysis of COVID-19 reported cases associated with the development of Takotsubo syndrome (TTS) [1]; however, we found two critical issues in reading your work.

Firstly, in the paper of Sala et al. [2], only a TTS pattern is described, rather than a reverse stress cardiomyopathy.

The 43-year-old female, with no previous cardiovascular disease, presented with oppressive chest pain; ST-segment elevation in leads V1, V2, and aVR with reciprocal ST depression in leads V4, V5, and V6 at ECG; elevation in cardiac and inflammatory biomarkers at lab exams; mild reduction of left ventricular function with hypokinesia of the mid and basal segments at transthoracic echocardiography and at dynamic $3 \mathrm{D}$ volume-rendering reconstruction of computer tomography; and absence of obstructive coronary disease at computed tomography angiography.

Although all these findings may be typical of both TTS and myocarditis, in order to clarify the diagnosis, Sala and colleagues referred the patient to perform both cardiac magnetic resonance and endomyocardial biopsy. After carrying out these investigations, according to the latest position statement of the European Society of Cardiology working group on myocardial and pericardial diseases [3], the final diagnosis was acute virus-negative lymphocytic myocarditis and not

This article is part of the Topical Collection on COVID-19

Andrea Falcetta

andrea.falcetta@gmail.com

Eleonora Bonfanti

bonfantieleonoris@gmail.com

Giuseppe Lauria

lauria.g@ospedale.cuneo.it

1 Division of Emergency Medicine, A.O. Santa Croce e Carle, University of Turin, via Michele Coppino 26, 12100 Cuneo, Italy

2 Division of Internal Medicine, A.O.U. Città della Salute e della Scienza, University of Turin, Corso A.M. Dogliotti 14, 10126 Torino, Italy
TTS complicated by myocarditis, as you reported. This patient should therefore be excluded from your systematic review.

In fact, despite the clinical presentation may be similar, TTS and myocarditis are two different entities (the former is a syndrome, and the latter is an inflammatory disease of the myocardium) with different diagnostic criteria, which allow differentiating one from the other.

In detail, to date, the diagnosis of TTS requires the fulfillment of all Mayo Clinic diagnostic criteria [4, 5], including the absence of myocarditis, so the diagnosis of the latter excludes that of TTS.

Secondly, although it may only be a typographical error, the paper by Taza et al. [6] described the development of TTS in a man of 52 years old and not of 82. Consequently, only 7 patients (instead of 8) were aged over 60 years old; moreover, the mean age of included patients may be slightly different from that reported in your systematic review.

Authors' Contributions All authors contributed to the drafting and approval of the manuscript.

Data Availability Not applicable.

\section{Compliance with Ethical Standards}

Conflict of Interest The authors declare that there is no conflict of interest.

Ethics Approval Not applicable.

Consent to Participate Not applicable.

Consent for Publication Not applicable.

Code Availability Not applicable.

\section{References}

1. Singh S, Desai R, Gandhi Z, Fong HK, Doreswamy S, Desai V, et al. Takotsubo syndrome in patients with COVID-19: a systematic 
review of published cases. SN Compr Clin Med. 2020;2:2102-8. https://doi.org/10.1007/s42399-020-00557-w.

2. Sala S, Peretto G, Gramegna M, Palmisano A, Villatore A, Vignale $\mathrm{D}$, et al. Acute myocarditis presenting as a reverse Tako-Tsubo syndrome in a patient with SARS-CoV-2 respiratory infection. Eur Heart J. 2020;41:1861-2. https://doi.org/10.1093/eurheartj/ehaa286.

3. Caforio ALP, et al. Current state of knowledge on aetiology, diagnosis, management, and therapy of myocarditis: a position statement of the European Society of Cardiology Working Group on Myocardial and Pericardial Diseases. Eur Heart J. 2013;34:263648. https://doi.org/10.1093/eurheartj/eht210.

4. Bybee KA, Kara T, Prasad A, Lerman A, Barsness GW, Wright RS, et al. Systematic review: transient left ventricular apical ballooning: a syndrome that mimics ST-segment elevation myocardial infarction.
Ann Intern Med. 2004;141:858-65. https://doi.org/10.7326/00034819-141-11-200412070-00010.

5. Prasad A, Lerman A, Rihal CS. Apical ballooning syndrome (TakoTsubo or stress cardiomyopathy): a mimic of acute myocardial infarction. Am Heart J. 2008;155:408-17. https://doi.org/10.1016/j. ahj.2007.11.008.

6. Taza F, Zulty M, Kanwal A, Grove D. Takotsubo cardiomyopathy triggered by SARS-CoV-2 infection in a critically ill patient. BMJ Case Rep. 2020;13:e236561. https://doi.org/10.1136/bcr-2020236561.

Publisher's Note Springer Nature remains neutral with regard to jurisdictional claims in published maps and institutional affiliations. 